\title{
情景教学法在对外汉语网络新词教学中的应用一以中高级水平 的汉语学习者为教学对象
}

\author{
孟雅喆 \\ 西北师范大学 \\ DOI:10.32629/er.v3i2.2451
}

[摘 要] 近年来,网络新词的推陈出新给对外汉语教师的词汇教学带来了新的挑战。只有与时俱进去适应网络新词的发展,把这部分内容加入 到教学当中才能够提高学习者用汉语进行交际的能力。在网络新词教学中运用形象生动的情景教学法会有效率地、有趣味性地提高学习者的 语言应用能力。本文通过调查问卷和口头访谈对汉语水平分别为初中高级的第二语言学习者对当前网络新词的应用情况进行了了解。以中高 级水平的汉语第二语言学习者为教学对象, 以不同课型为例展开了情景教学法在对外汉语网络新词中如何应用的教学策略。

[关键词] 对外汉语教学; 情景教学法; 网络新词; 教学研究

\section{1 网络新词的发展}

1. 1 在汉语当中对网络新词的界定

1.1.1广义的网络新词

广义上网络新词包括三类, 其中一是指网络专业术语, 如新媒体、汶览 器、杀毒、复制、菜单等; 二是由于互联网的普及, 与互联网服务相关的 人们用与交流的新词语, 如网名、网吧、二维码等; 三是在社交软件的互 动中而逐渐形成的网络流行语, 如酱紫、886、晒、打酱油等。

1. 1.2 狭义的网络新词

主要是指在各种社交软件等相关新媒体领域中交流互动时所新创的 交际符号, 狭义的网络新词是指是广义网络新词所指的第三种,包括字母、 词语、缩写、表情包、数字、谐音等。

1.2网络新词的特点

\subsection{1表达随意, 缺乏规范}

网络新词不符合汉语特定的造词法, 而是网民在使用网络进行交流的 过程中随意创造的, 所以网络新词缺少规范制约的造词因素。纵观近些年 出现的网络新词, 百分之五十以上的网络新词是不符合现代汉语语法规范 的。比如 “什么”, 在网络上, 人们喜欢用 “神马” 来代替, “神马” 从汉 语的语法意义上来讲和 “什么” 是没有任何联系的, 只是因为在某些方言 中与 “什么”的发音接近。

\subsection{2言简意赅, 传播迅速}

网络新词在使用时基本都是即时性的, 它讲求交流的效率, 不像书面 语那么严谨, 还需经过仔细的推敲与选择。现如今人们为了增加聊天的趣 味性, 就创造出了许多具有想象力的网络新词。网络新词大都用数字、同 音词、字母通过谐音的方式来表达所蕴含的意义, 如把 “同学” 说成 “童 鞋”、“3Q”表示 “谢谢”等等。

\subsection{3生动形象, 幽默诙谐}

网络新词比传统的一般词汇更加生动形象, 具有趣味性, 将诙谐与调 㑆的色彩表现得淋漓尽致, 渐渐地, 这些网络新词就成为了朋友之间互相 调㑆和自嘲的标志, 如 “俊白甜”、“女汉子”、“吃瓜”、“网红”、“奥利给” 等。这些词不仅生动形象表现了事实, 还非常具有幽默感。

\section{3汉语学习者对网络新词的掌握情况}

我们用问卷调查的形式, 以初中高级的汉语学习者为调查对象, 分 析了他们对2008- - 2020年具有代表性的汉语网络新词的掌握情况。调 查问卷是以苏丹的汉语第二语言学习者而进行的, 本次调查问卷一共发 放 38 份, 回收到的问卷有 35 份, 回收率是 $92 \%$, 有效的问卷有 34 份, 有效率
为 $91.42 \%$ 。得出的结论有: 第一, 网络新词是中级班和高级班的汉语第 二语言学习者才会接触到的, 他们对汉语的理解程度和运用水平相比较初 级水平的汉语学习者是很高的。第二, 一部分留学生在汉语学习过程中接 触过这些词语, 但是教材中并没有这些词的出现, 他们一般都是通过网络 以及中国朋友学习到这些新词。第三, $65 \%$ 的学习者表现出了对网络新词浓 厚的兴趣, 觉得网络新词很有趣, 希望通过网络新词的学习, 提高自己的汉 语交际的水平。

\section{2 情景教学法在网络新词教学中的具体应用}

2. 1 听力课

听力课对对外汉语网络新词的教学也非常重要, 在安排听力课的环节 时, 教师应当选择学习者容易理解的词汇。从前文所分析出来的网络新词 的特点, 我们知道了到许多网络新词都是根据谐音发展而来的, 所以, 网络 新词的学习对学习者的听说能力要求相对较高。不论是谐音网络新词还是 其他类型的网络新词, 听力课都应该以多种形式呈现在学习中的学习课堂 当中, 其中, 情景教学法最为实用, 教师呈现出一个具体的情景比讲述词语 的含义要便于理解。

例: “俊白甜”。

老师给出电视剧《杉杉来了》听力材料 “我人俊, 就多做功课多努力。 大家说什么是大家的自由, 让大家看到我的努力, 不去相信那些歪曲的事 实, 才是我的本事”。问: “根据这个女生所说的, 我们可以用以下哪一个词 来形容她呢?”

$\begin{array}{llll}\text { A. 女汉子 } & \text { B. 俊白甜 } & \text { C. 心机girl } & \text { D. 女神 }\end{array}$

“俊白甜”一词通常指很可爱并且让人感觉很温馨, 但是却经常俊乎 乎的被人算计。A答案 “女汉子” 指性格爽快, 行为举止和像男生的女生。 C答案 “心机girl” 指心机很重的女生。D答案 “女神” 指非常漂亮且有气 质的女生形象。

\section{2 口语课}

口语课是为了让同学们在课堂当中通过对口语的训练加强学习者的 交际能够, 从而更好地提高学习者用目的语进行交际的能力。关于网络新 词的教学我们面对的对象是中高级水平的汉语学习者, 在《准高级汉语口 语・下》里面的《电脑与网络》一课中曾出现过 “ 886 ”、555555”、“菜鸟”、 “MM”、“大虾” 等网络新词。随着网络新词的发展和它在人们的日常生活 中的渗透, 它在口语中出现的频率也不断增多, 学习者如果对这些网络新 词不是足够了解的话, 会在沟通当中产生障碍甚至是闹笑话。教师要在口 语教学前, 通过这些新词的特点来设置不同的教学环节以及内容导入, 生 
动形象、谈谐幽默, 让学习者达到会说会用的状态。

2. 3 阅读课

阅读课的重点是学生读, 教师主导学生做题为主, 纠错为辅, 避免单一 沉闪。如果网络新词出现在汉语初学者的课本当中, 会对学生造成一定的 混淆, 不利于学习。但是对于中高级水平的汉语学习者而言, 在阅读课中网 络新词教学不但可以加强学习者对汉语发展的整体认知, 还可以为提高学 习者阅读汉语文章的能力。教师可以给出相应的情景来让学习者在阅读理 解之后的选择和回答来了解。

例 1: “给力”。

“今年的运动会报名的人好多, 尤其是我们学院的留学生, 他们取 得了五个项目的冠军, 真是太给力了!”问：课文中夸运动员 “给力” 中 的 “给力” 是什么意思? A. 力气大 B. 有趣C. 优秀D. 开心。根据上文中取 得了五个项目的冠军, 联系上下文可以得出 “给力” 是非常棒, 很优秀的 意思。

例2: “㘣”。

在《发展汉语 - 高级阅读1》中有一篇《网络新词 “㘣”》的阅读课当 中, 虽然“㘣” 字看起来十分难, 不仅发音难, 写法也难, 但是根据文章内容 发现它其实还是很有趣的, 从它象形的外表来看, 可以用谐音的 “若” 义来 解释, 学生会觉得汉字很好玩, 一个字可以表达多种含义, 这时教师可以运 用情景教学法引导学生理解该词的意思, 也可以根据上下文扩展一些相关 的网络新词以供学习者学习。

\section{4 写作课}

在学习者学习汉语的过程中, 最好不要在写作中出现太多的网络新 词。因为在第二语言学术界对网络新词的态度襄贬不一, 尤其在写作课中 最好尽量少出现, 并且在写作课中主要是学生的独立思考, 也进行叙述, 教 师的参与成分比较低, 所以如果学生出现什么语法错误, 教师不能立马解 决。对于学习者而言, 应当以严谨的书面语作为参考进行写作。

\section{5 综合课}

在综合课上,教师不用专门找一篇文章来单独进行网络新词的集中教 学, 教师可以在导入过程中, 设计一个情景引出这个网络新词, 将网络新词 穿插在课文中不但省时省力, 还能让学习者得到最好的学习效果。关于网 络新词的综合课教学, 还是以实用性为主, 语法点为辅, 如果将网络新词单 独作为一部分进行教学, 在教学设计上会非常困难, 而且过多的连续输入 会导致学习者对词义的混淆。

例: “驴友”。

在《发展汉语 (第 2 版) - 高级综合 1 》中第八课-—《享受旅行》中, 教师在导入新课时可以先问同学们喜不喜欢旅游, 是喜欢跟着旅游团走马
观花的游览风景, 还是喜欢自己一个人背着包, 走走停停, 感受大自然做一 个背包客或者 “驴友”。通过这种方式带入网络新词, 可以根据教师的提示 让学生先说说自己对于 “驴友” 的理解, 然后再将正确的标准的意思传达 给学生, 在之后的练习中再加入对于该词的复习和巩固就可以了。

\section{3 情景教学法在对外汉语网络新词教学中的教学反思}

3. 1 选择适当的教学对象

虽然网络新词被新时代的人们广泛地运用在日常交际中, 但是它的使 用范围并没有具有全民性, 也不能成为基本词汇。对于年轻的汉语第二语 言学习者而言, 他们日常生活中最不可或缺的就是网络, 所以他们对网络 新词固然会有学习的需求, 但是不经常上网的中老年人或小孩子而言, 他 们对网络新词理解能力较差, 不感兴趣的话是不建议教师引入教学。

3.2 采取恰当的教学方法

每个网络新词都有其创作来源, 对外汉语教师只有了解了这些词的创 作方式、来源和基本用法, 使用准确的教学方法才能够让同学们深刻记忆。 情景教学法尤其有帮助, 情景教学法能通过具体情境的设定更有效的帮助 学习者掌握网络新词, 进而实现交际。

3. 3 选取合适的教学内容

如果教师想要让学生理解并灵活运用网络新词, 应该多从课堂教学上 下功夫, 教师如果在课堂中采取灵活多样的情景教学法进行网络新词教学, 则会产生事半功倍的效果。我们在不同的汉语水平学习者中应该进行不同 的教学, 因此应该选择适合交际和在日常生活中常见的网络新词。在高级 阶段的汉语课程上, 此时的汉语第二语言学习者的听说读写能力已经达到 了很高的水平, 则应在听说读写中都强调对网络新词的教学, 最后做到能 让学习者能够灵活准确地运用网络新词。

\section{[参考文献]}

[1]陆丹妮. 对外汉语教学中的网络新词教学策略探析[J]. 语文学 刊,2015,(02):153-154.

[2]李乐.对外汉语高级听说课网络新词教学研究[D]. 青岛大学,2017,(1):49.

[3] 刘静. 基于情景教学法的对韩初级汉语综合课教学设计[D].渤海大 学,2016,(08):47.

[4]刘小梅.网络新词语对外汉语教学[J].辽宁行政学院学报,2011,(8):105.

[5]郭伏良,赵艳平.网络新词“卡哇伊”[J].语文建设,2013,(7):173.

[6]祖迪.网络新词语与对外汉语教学[J].鸡西大学学报,2013,13(1):1-2.

作者简介：

孟雅喆(1997--),女,汉族,甘肃兰州人,汉语国际教育专业硕士在 读,单位: 西北师范大学国际文化交流学院汉语国际教育专业,研究方 向: 汉语国际教育。 